\title{
МОДУЛЬНОЕ ОБУЧЕНИЕ МОНОЛОГИЧЕСКОЙ РЕЧИ СТУДЕНТОВ ЛИНГВИСТИЧЕСКОГО ПРОФИЛЯ
}

\section{MODULAR TEACHING MONOLOG METHOD FOR STUDENTS OF LINGUISTIC SPECIALTIES IN THE ASPECT OF THE INTERCULTURAL PARADIGM OF FOREIGN LANGUAGE EDUCATION}

\section{Myltseva}

Summary: The article highlights the issues of organizing modular training in students' monolog - junior linguists. According to the author, the system of modular training in monolog contributes to the consistent development of verbal communicative competence. It is necessary for future specialists for professional communication in the context of international cooperation and intercultural communications. The author reveals the concept and features of modular learning and, based on comparative analysis, substantiates its advantages over the traditional system of monolog teaching. It is emphasized that the modular training system is based on modern scientific theories and innovative practices that enrich the traditional learning model, which is reflected in the continuity of the tasks and training content at each stage of professional foreign language education.

Keywords: monolog, monologic communication, modular training, speech communicative competence, professional communication.
A ктуальность исследуемой проблемы определяется высокими требованиями ФГОС ВПО нового поколения к уровню профессиональной подготовки студентов лингвистического профиля. В стандарте указывается на то, что лингвист должен уметь осуществлять межкультурное общение в различных профессиональных сферах, выполнять функции посредника в сфере межкультурной коммуникации, проводить деловые переговоры, быть активным участником конференций, симпозиумов, семинаров с использованием нескольких рабочих языков, проводить информационно-поисковую деятельность, направленную на совершенствование профессиональных умений в области межкультурной коммуникации.

Требования стандарта нового поколения вполне справедливы и обусловлены динамикой международного сотрудничества российских и зарубежных странпартнеров, которая свидетельствует о расширении совместных инновационных проектов в сферах образования, экономики и производства. Ориентация процесса обучения монологической речи на межкультурную профессиональную коммуникацию вызывает к необходи-

\author{
Мыльцева Маргарита Викторовна \\ Российский университет дружбы народов \\ margarita1405@yandex.ru
}

Аннотация: В статье освещаются вопросы организации модульного обучения монологической речи студентов - лингвистов младших курсов. По предположению автора, система модульного обучения монологической речи способствует последовательному развитию речевой коммуникативной компетенции, необходимой будущим специалистам для профессионального общения в условиях международного сотрудничества и межкультурных коммуникаций. Автор раскрывает понятие и особенности модульного обучения и на основе сравнительно-сопоставительного анализа обосновывает его преимущества перед традиционной системой обучения монологической речи. Подчеркивается, что система модульного обучения строиться на современных научных теориях и инновационных практиках, обогащающих традиционную модель обучения, что находит свое отражение в преемственности задач и содержания обучения на каждом этапе профессионального иноязычного образования.

Ключевые слова: монологическая речь, монологическое общение, модульное обучение, речевая коммуникативная компетенция, профессиональная коммуникация.

мости внедрения в практику иноязычного образования наиболее эффективных методов обучения, мотивирующих студентов к овладению практическими навыками монологической речи, и в полной мере учитывающих их возрастные и психологические особенности. Одним из таких методов является модульное обучение, обеспечивающее динамичность, гибкость, преемственность учебного процесса, возможность самостоятельной творческой работы студентов, самоконтроль собственных достижений в практическом использовании приобретенных навыков и умений монологической речи.

Исследование вопросов применения модульного метода в обучении монологической речи потребовало обратиться к научным источникам, освещающим историю его создания и внедрения в иноязычное образование. Как стало известно, научный интерес к модульному обучению иностранному языку особенно возрос в условиях становления межкультурной парадигмы иноязычного образования. Это позволило выявить его преимущественные характеристики, методической и дидактической потенциал и ответить на вопрос о целесообразности использования модульного метода в об- 
учении монологической речи студентов-лингвистов в условиях расширяющейся межкультурной профессиональной коммуникации.

Межкультурная профессиональная коммуникация предполагает владение лингвистами иноязычной коммуникативной компетенцией, включающей в себя свободное владение всеми видами речевой деятельности и профессиональное общение. Профессиональное общение осуществляется в форме диалогической и монологической речи. Владение монологической речью является личностно - и профессионально значимым речевым умением, с помощью которого специалисты свободно ведут деловые беседы, делают доклады и публичные сообщения, презентации в power point и беспрепятственно участвуют в обсуждениях хода и перспектив совместной деятельности. Такие типы монологических высказываний студенты должны осваивать, начиная с начальных курсов обучения для того, чтобы на старших курсах (и во время обучения в магистратуре, а затем в аспирантуре) свободно работать с информацией научных текстов. Преемственность и непрерывность обучения монологической речи должны рассматриваться как приоритетные принципы иноязычного профессионального образования.

Изучение интересующей нас проблемы показало, что выполнение требований к уровню подготовки студентов, установленному стандартом в области монологической речи, осуществляется традиционно на основе учебного материала учебно-методических комплексов и учебных пособий по иностранному языку, рекомендованных для лингвистических факультетов, которые не могут удовлетворять запросам студентов одновременно всех направлений специализаций. Последовательная работа студентов с дополнительным учебным материалом, широко представленным в глобальной сети интернет, и отличающимся актуальностью, высокой информативностью, научностью, достоверностью, могла бы способствовать эффективному развитию умений монологической речи.

В ходе исследования удалось установить, что в процессе работы с текстами больше внимание уделяется работе с грамматическими структурами и лексическими единицами, а не формированию практических навыков построения монологической речи с учетом ее коммуникативных функций.

В беседе со студентами младших курсов удалось выявить трудности, которые они испытывают при подготовке монологического высказывания. Все трудности связаны, прежде всего, с психологическими факторами (отсутствие мотивации, боязнь сделать ошибки, неуверенность в правильности выражения своих мыслей, и др.), а также с недостаточным опытом работы с текстом с соблюдением всех этапов построения монологического высказывания.

Очевидным становится то, что развитие монологической речи должно осуществляться с помощью определенной методической системы, которая включает принципы обучения, отбор тематики в соответствии со специализацией студентов-лингвистов, комплекс упражнений и форм работы, соответствующую структуру занятий по иностранному языку.

Таким образом, актуальность исследуемой проблемы обусловливает необходимость переосмысления методической системы обучения монологической речевой деятельности студентов-лингвистов, ориентированной на профессиональное общение и межкультурную профессиональную коммуникацию. В свою очередь это позволит устранить противоречия между целевыми установками на обучение монологической речи для будущей профессиональной деятельности студентов и методами их реализации в процессе обучения иностранному языку.

Научная новизна и наиболее значимые результаты, которые удалось получить в ходе данного исследования, заключаются в том, что создана научно-обоснованная концепция модульного обучения монологической речи студентов начальных курсов лингвистических специальностей, ориентированная на формирование культурной языковой личности лингвиста, обладающей способностью к монологическому общению в условиях международной профессиональной коммуникации; разработана модель уровневого развития монологической компетенции с учетом возрастных и психологических особенностей личности студента; создана методическая система модульного обучения монологической речи, реализующая предложенную соискателем модель, и обеспечивающая дифференциацию и индивидуализацию учебного процесса; разработана образовательная программа краткосрочного обучения преподавателей иностранного языка методике применения модульного метода обучения монологической речи студентов начальных курсов лингвистических специальностей.

Целью исследования является создание межкультурной методики модульного обучения монологической речи студентов младших курсов лингвистических специальностей.

В соответствии с выдвинутой целью были определены следующие задачи:

- Изучить и проанализировать факторы, влияющие на выбор модульного метода обучения

- Раскрыть дидактический потенциал модульного метода обучения и обосновать методическую целесообразность его применения в обучении монологическому общению 
- Создать научно-обоснованную концепцию модульного обучения монологической речи

- Спроектировать и сконструировать уровневую модель модульного овладения студентами монологической коммуникативной компетенцией.

Выбор модульного метода в качестве методологической основы обучения монологической речи обусловлен рядом факторов. Одним из основных аргументирующих факторов является низкий уровень сформированности у многих студентов умений монологического общения, практических навыков проектирования и структурирования материалов публичных выступлений, их донесения до слушателей в виде докладов, сообщений, презентаций на международных студенческих мероприятиях. Bсе больше студентов, судя по итогам проведенного опроса, осознают необходимость владения монологическим общением. Но как сделать этот процесс эффективным?

В научных исследованиях и публикациях отечественных и зарубежных ученых достаточно много внимания уделялось и уделяется новым методам в обучении иностранному языку студентов лингвистических специальностей, в том числе, модульному обучению. Известно, что вопросы модульного обучения иностранному языку являлись предметом исследования многих отечественных и зарубежных ученых [3, с.225-226; 4, с.1133-1135; 6, с.213-216; 7, с.26-27; 197, с. 215-234 и др.]. Ученые полагают, что модуль - это независимый элемент в сформированной системе типов организации и осуществления учебно-познавательных действий, призванных оказать помощь студентам-лингвистам в процессе достижения ими поставленных целей. Основоположник «модульного обучения» как процесса обучения на всех уровнях образования в целом и на уровне высшей школы в частности, Дж. Расселл [13, с.19-21] трактует понятие «модуль» в обучении как совокупность учебных информационно-аналитических материалов, которая лежит в области концептуальной плоскости, а также, - определенных операционных действий студентов во время образовательного процесса.

Российские ученые в своих исследованиях приходят к выводу о том, что модуль являет собой обобщенное множество самых разных видов и форм образовательного процесса, которое направлено на постижение определенного раздела курса обучения или его какой-либо насущной задачи.

Специализированное учреждение Организации Объединенных Наций (UNESCO - United Nations Educational, Scientific and Cultural Organization) по вопросам образования, науки и культуры (1998) определяет данное понятие в виде самостоятельного (изолированного) «портфолио» обучающих материалов, способствующего индивидуализации образовательного процесса. Анализируя пред- ставленные трактовки понятия «модуль», и не смотря на различия в их трактовках различными зарубежными и российскими учеными, мы можем их классифицировать с различных позиций: первая, которая определяет понятие «модуль» в контексте совокупности различных учебных дисциплин государственного учебного плана по конкретной специальности; вторая, - рассматривающая термин «модуль» в виде организационного множества и методической междисциплинарной совокупности, представляющих собой объединение разнообразных тематических частей разных учебных дисциплин; третья, - трактующая дефиницию «модуль» в виде совокупности организационного и методического множества в системе конкретной учебной дисциплины.

Опираясь на научно-теоретическую базу исследований вопросов, связанных с сущностью понятия модуля и модульного обучения, суммируя сказанное, будем придерживаться определения модуля как самостоятельной организационно-методической структуры конкретной учебной дисциплины, состоящей из таких компонентов, как: цель, набор учебного информационно-дидактического материала, технологическое обеспечение и оценочная система.

Перейдем к рассмотрению ретроспективы «модульного обучения». Прежде всего, следует отметить, что идея осуществления процесса обучения в форме модулей возникла в результате разрушительных процессов в экономике, культуре и образовании в период второй мировой войны. Остро стояли вопросы подготовки квалифицированных специалистов для всех секторов экономики. Необходимо было сосредоточить внимание на разработке новых и эффективных методов обучения, позволяющих ускоренно обучать работников, востребованных на рынке труда. Одним из таких методов стал метод модульного обучения, разработанный американскими учеными, и предложенный педагогическому сообществу. Основная идея модульного обучения усматривалась в том, чтобы предоставить специалистам возможность выбора курса обучения для совершенствования практических навыков и приобретения новых компетенций или получения дополнительной квалификации. Действенным импульсом массового внедрения в образовательный процесс технологий «модульного обучения» на Западе явилась научно-практическая и методическая конференция ЮНЕСКО, которая состоялась в столице Франции в 1974 г. В постановлении конференции содержались следующие рекомендации:

- разработать и создать комплексы «открытых и гибких структур образования», дающих возможность быстрой адаптации к социально-экономическим и политическим трансформ;

- внедрить данные разработки в сферу науки с учетом специфических особенностей каждого направления и т.д. 
Всем этим рекомендациям и отвечала предложенное мировому педагогическому сообществу концепция - «модульное обучение», так как только оно давало возможность сущностным изменениям, как структур, так и содержаний информационно-аналитических учебных материалов, расположенных в виде комплексных блоков. Также оно обобщало самые разные структуры и содержания процесса обучения в целом, и монологической речи студентов-лингвистов в частности.

Исходя из этого, студенты имели и имеют по настоящее время право отбирать наиболее соответствующие их личностным особенностям информационные блоки учебного материала индивидуализированного толка.

Многие зарубежные ученые и практики используют «модульное обучение» монологической речи в самых разных направлениях. Одни исследователи [9, с.11-12; 11, c.17] применяли этот метод для того, чтобы студентам было бы продуктивно совершать учебные действия с наиболее комфортной скоростью, выбирать наиболее нужный и адекватный их личностным учебным способностям тип образовательного процесса; другие [10, с.7; 12 с с. 7; 13, с.19-21] использовали этот метод обучения для выявления у студентов наиболее эффективных позиций в образовании, а также для предоставления им возможности обучаться самостоятельно, применяя «корректирующие модули»; некоторые [6, с.213-216; 8, с.62] предлагали и использовали в своей практике «модульное обучение» в контексте структурирования информационно-обучаемого материала из уже созданных «языковых единиц». В исследовании психолога К.Я. Вазиной [1,с.21-24] понятие модуля трактуется в контексте методических приемов отображения внешнего мира в его внутренней сущности. Ученый полагает, что «модуль» представляет собой индивидуализированную конкретную технологию личностного развития, как преподавателя, так и студента высшей школы в сфере лингвистики.

Построение учебных программ на основе принципов модульного обучения обеспечивает преемственность развития умений монологической речи, общую связность и прозрачность содержания обучения, последовательное продвижение от более низкого к более высокому уровню монологической компетенции. Прогресс в овладении монологической речью особенно четко проявляется в способности студента участвовать в реальной коммуникативной деятельности и пользоваться коммуникативными стратегиями.

Стратегии, как указывается в документе Общеевропейские компетенции владения иностранным языком» [5, с.55] - это средство, которое применяет пользователь языка для мобилизации и сбалансирования своих ресурсов, активизации навыков и умений с тем, чтобы справиться с конкретной ситуацией общения и успешно ре- шить определенную коммуникативную задачу наиболее полным и в то же время экономным и доступным путем в соответствии со своей целью. Поэтому коммуникативные стратегии являются основанием для определения уровня владения говорением в его диалогической и монологической форме.

Большинство исследователей полагает, что модульное обучение монологической речи представляет собой дидактическую систему как единство обучения и самостоятельной творческой речевой деятельности студентов с целью овладения умениями монологического общения, реализующуюся в особых ее единицах - модулях.

Система модульного обучения обеспечивает непрерывность и преемственность обучения монологической речи и создает реальные условия для последовательного освоения студентами практических навыков монологического общения. являющихся основными компонентами иноязычной монологической коммуникативной компетенции.

Модульный метод, обладающий гибкостью и способностью к интеграции с другими методами в обучении иноязычной устной речевой деятельности, во взаимосвязи с деятельностным методом является реальным мотивирующим средством развития практических навыков монологической речи; стимулирует активную мыслительную деятельность за счет обеспечения дифференциации и индивидуализации процесса овладения монологическим общением. Эта особенность находит отражение в принципах - методологических положениях, определяющих процесс модульного обучения монологической речи студентов лингвистических специальностей (схема 1.1.1)

Как наглядно представлено в схеме, основными принципами модульного обучения являются:

- принцип коммуникативной направленности обеспечивает монологическое общение;

- принцип динамичности и гибкости ориентирует процесс обучения на личность студента, позволяет своевременно корректировать содержание в соответствии с возрастными и психологическими особенностями студентов, вносить изменения и дополнения в планирование, принимать во внимание интересы и потребности студентов в последовательности овладения речевыми умениями;

- принцип приоритета самостоятельной творческой работы студентов в освоении содержания модуля с применением информационных и мультимедийных технологий (подготовка презентации, выступления с наглядным сопровождением, реферата, доклада и др.) содействует развитию креативного мышления, способности к прогнозированию, предвосхищению, проектированию, планированию и саморефлексии; 
Схема 1.1.1

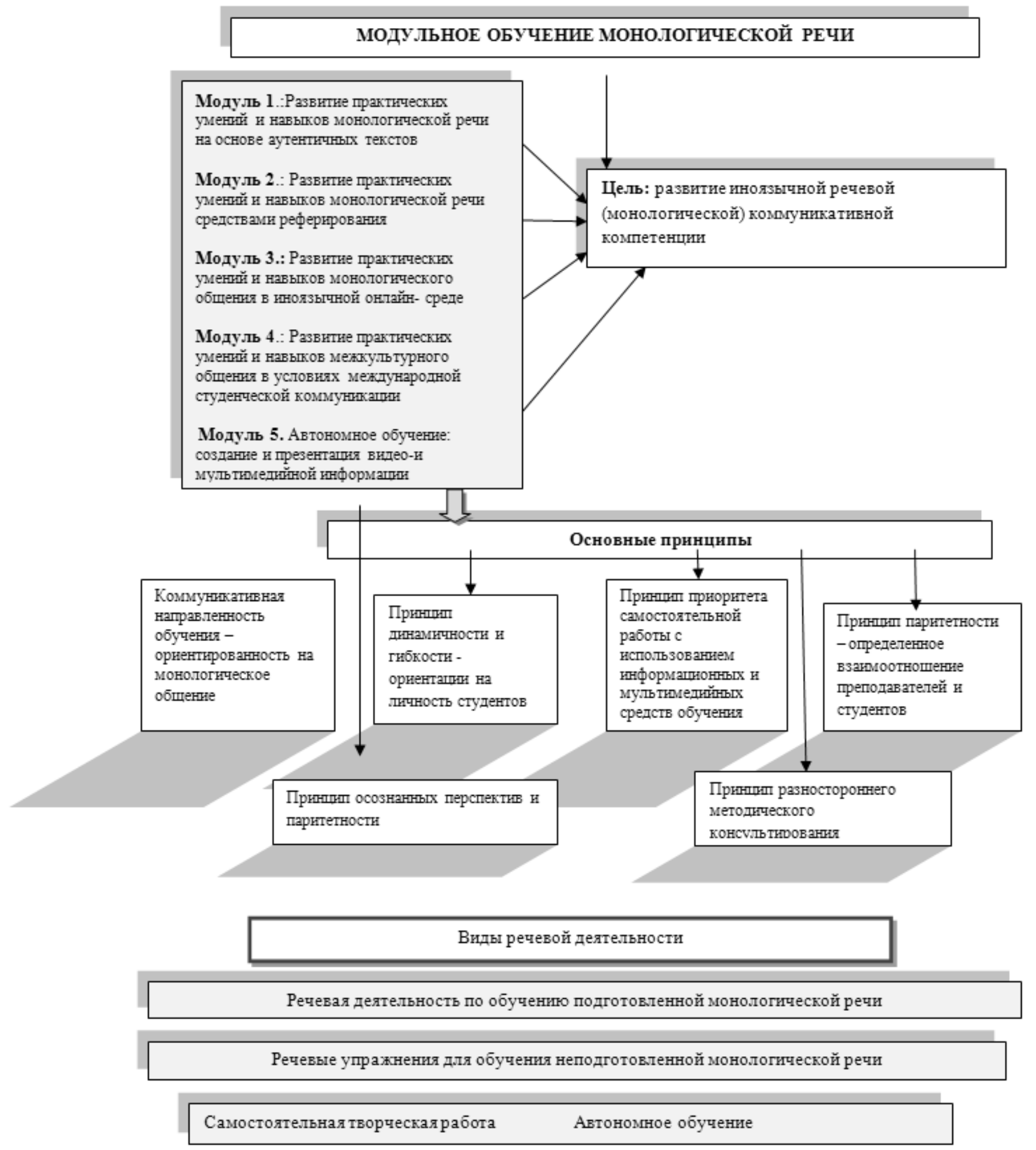

- принцип паритетности предполагает сотрудничество преподавателя и студентов, при котором активную позицию занимает студент, а преподаватель оказывает педагогическую поддержку при решении поставленной задачи;

- принцип осознанных перспектив и паритетности направлен на осознание студентами необходи- мости овладения монологической речью для будущей сферы профессиональной деятельности, формирование способности к глобальному (стратегическому) мышлению и готовности к международной профессиональной коммуникации;

- принцип разностороннего методического консультирования предусматривает своевременную 
консультативную помощь, рекомендации преподавателя студентам по выполнению заданий или организации самостоятельной работы.

Содержание первого модуля ориентировано на развитие практических умений и навыков монологической речи на основе аутентичных текстов разного вида и жанра, имеющих определенную целевую установку. Для того, чтобы развить у студентов практические навыки монологических высказываний, необходимо научить их анализировать жанровые, структурные, языковые особенности речевых произведений. При этом могут осуществляться следующие виды деятельности: чтение написанного текста вслух; речь, основанная на конспекте, написанном тексте или виртуальных пособиях (диаграммах, картинах, таблицах и т.д.); неподготовленная речь; развернутый монолог: приведение доводов, например, во время дебатов; публичные сообщения.

Целевым предназначением второго модуля является поэтапная работа с тестовым материалом для подготовки доклада или сообщения. Работа с текстом осуществляется через систему заданий, которые выполняются в процессе реферирования текста. Реферирование как вид речевой деятельности предполагает восприятие, осмысление, критический анализ, отбор нужной информации и монологическое высказывание по проблеме, заключенной в данном тексте.

Третий модуль направлен на самостоятельную работу студентов с текстами электронного учебника или пособия, содержащих задания и упражнения разной сложности, позволяющих подготовиться к монологическому общению в рамках избранной темы. В модуле предусматривается задание по разработке презентации с использованием ресурсов интернета.

В четвертом модуле ставится цель развития практических навыков и способности личности студента к межкультурному монологическому общению в ситуациях международной коммуникации. В рамках данного учебного курса отрабатываются сценарии знакомства и представления себя, своих интересов и образовательных намерений, обмен информацией через систему скайп и электронное письмо, проведение виртуального семинара с выступлениями по актуальным проблемам студенческой молодежи.

Пятый модуль рассчитан на автономное обучение студентов с последующим представлением в группе своей работы, направленной на самосовершенствование и саморазвитие коммуникативных умений и речевых навыков монологической речи. Студентам предоставляется право выбора образовательных технологий и осуществляется педагогическая поддержка в виде консультирования по использованию учебных печатных и электронных текстовых материалов, выполнению заданий и упражнений, подготовке монологических произведений.

Продвигаясь от модуля к модулю, студенты наращивают коммуникативные умения и речевые навыки монологического общения на каждом уровне овладения иностранным языком. Прогресс в овладении монологической речью особенно четко проявляется в способности студентов участвовать в коммуникативной деятельности и пользоваться коммуникативными стратегиями, являющимися средством мобилизации своих ресурсов, активизации своих умений, чтобы справиться с конкретной ситуацией общения.

Суммируя сказанное, мы пришли к следующим выводам.

Изучение теоретической и практической значимости модульного метода в обучении монологической речи студентов начальных курсов лингвистических специальностей показало, что система модульного обучения мобильна и обеспечивает преемственность уровней и последовательность овладения студентами монологической коммуникативной компетенцией.

Теоретическая значимость результатов исследования заключается в том, что они дополняют теорию и методику профессионального иноязычного образования новыми знаниями о методе модульного обучения, который преподаватели иностранного языка могут успешно использовать для обучения речевой (монологической) деятельности в аудиторное и внеаудиторное время; представлениями о взаимосвязи монологической речи с другими видами речевой деятельности; дидактическом потенциале модульных программ обучения на каждом уровне овладения монологической коммуникативной компетенции. Практическая значимость результатов исследования заключается в том, что применение метода модульного обучения монологической речи с учетом начального уровня готовности студентов к монологическому межкультурному общению, повышает эффективность овладения студентами монологической коммуникативной компетенцией как средством межкультурной коммуникации.

В заключении хотелось бы подчеркнуть, что в методической науке все изменения связаны с переходом к межкультурной парадигме иноязычного образования. Свидетельством этому является появление многочисленных научных работ и публикаций, отражающих новый взгляд на обучение монологической речи (подготовленной и неподготовленной). Межкультурная парадигма отражает систему теоретических и методологических положений в научной области межкультурного образования, целью и результатом которого является вторичная язы- 
ковая личность, обладающая готовностью к межкультурной профессиональной коммуникации в условиях международного сотрудничества.

При разработке научно-обоснованной концепции модульного обучения монологической речи выявлен методический и дидактический потенциал метода модульного обучения монологической речи. Через ряд аргументированных доказательств теоретически обосновано, что модульная система обучения иностранному языку отличается от традиционной системы гибкостью и вариативностью, последовательностью и уровневостью овладения речевой монологической коммуникативной компетенцией. Учебный материал распределяется дозировано по модулям, что дает возможность постепенно вовлекать студентов в разнообразные виды коммуникативной и речевой деятельности, связанной с овладением монологической речью. Студенты учатся не только передавать содержание прочитанных текстов или рассказывать о событиях, но и обосновывать свое мнение, аргументировать и приводить доводы, подкрепляя собственную точку зрения развернутыми дополнительными утверждениями. В ходе опытно-экспериментального обучения подтвердилась правильность положения концепции о том, что модульное обучение предполагает в большей степени парную и групповую формы работы на занятиях, так как его главным ориентиром является развитие речевой монологической коммуникативной компетенции студентов. Развитие речевой монологической коммуникативной компетенции обеспечивается системой репродуктивно-продуктивных и продуктивных упражнений для развития речевых умений неподготовленной и подготовленной монологической речи. Эти задачи не рассматривались в рамках данной статьи и являются дальнейшей перспективой исследования.

ЛИТЕРАТУРА

1. Вазина К.Я. Саморазвитие человека и модульное обучение. - Н. Новгород, 1991.- С.21-24

2. Гальскова, Н.Д., Тарева Е.Г. Ценности современного мира глобализации и межкультурное образование как ценность // ИяШ. 2012. № 1. С.6

3. Кузовлева Н.Е. Модульная программа обучения английскому языку //Современные технологии обучения в высшей школе: Материалы конференции Хабаровск, 2012.- С. 225-226

4. Култаева Ф.Э. Использование модульной технологии в обучении иностранному языку студентов технического вуза // Молодой ученый. 一 2016. — №8. —C. 1133-1135. — URL https://moluch.ru/archive/112/28629/ (дата обращения: 08.02.2020).

5. Общеевропейские компетенции владения иностранным языком: Изучение, преподавание, оценка Текст. Cambridge University Press, МГЛУ, 2003.-256c.

6. Сидакова Н.В. Принцип системности в технологии модульного обучения иностранным языкам // Азимут научных исследований: педагогика и психология.- 2016.- Т.5.- №4 (17).- С. 213-216.

7. Ц Цыбанёва В.А. Модульное обучение иноязычной аудитивной компетенции студентов-лингвистов: английский язык как второй иностранный: диссертация ... кандидата педагогических наук: 13.00.02 / Цыбанёва Валентина Александровна - Волгоград, 2009.- С.26-27 (185 c.)

8. Ч Чошанов, М.А. Гибкая технология проблемно-модульного обучения [Текст]: методическое пособие/ М.А. Чошанов. — М.: Нар. образование, 1996. — С.16-17

9. Юцявичене П.А. Теория и практика модульного обучения. Каунас: Швиеса, 1989. С. 62.

10. Юцявичене П.А. Принципы модульного обучения // Советская педагогика. -1990. -No1. -C. 55 -60.

11. Goldshmid B., Goldshmid M.L. Modular Instruction in Higher Education // Higher Education. - 1972. - №2. P.11-12

12. Owens G. The Modele in «Universities Quarterly»// Universities Quarterly, Higher education and society. 1975 - Vol. 25. - № 1. P.7

13. Postlethwait S.N. Time for Microcourses // The library-college Journal. 1969.-Vol. 2,-№2. P.17

14. Russell I.D. Modular Instruction. - Minneapolis, Minn., Burgest Publishing Co., 1974. P.19-21

(с) Мыльцева Маргарита Викторовна (margarita1405@уandex.ru). Журнал «Современная наука: актуальные проблемы теории и практики» 